\title{
ORden, PODER y CONTRABANDO EN EL CARIBE DURANTE EL MEDIO SIGLO ANTES DE LA INDEPENDENCIA
}

ORDER, POWER AND SMUGGLING IN THE CARIBbEAN HALF A CENTURY BEFORE INDEPENDENCE

Por: Ruth Esther Gutiérrez Meza*

\section{* RUTH ESTHER} GUTIÉRREZ MEZA

Magister en Historia. Docente Universidad de Cartagena. Facultad de Cien cias Humanas. Programa de Historia. Miembro del grupo de investigación Frontera, Sociedad y Cultura en el Caribe y Latinoamérica de la Universidad de Cartagena (Colombia). Reconocido por COLCIENCIAS Categoría A1. E-mail regmy@hotmail.com

. -}

les permitieron beneficiarse del contexto político y económico que les rodeaba.

Palabras clave: Caribe, intercambios mercantiles, prácticas sociales y contrabando.

\section{ABSTRACT}

The Colombian Caribbean region has historically being characterized by the diversity, heterogeneity and geographic importance it has for business and trade. During half of the century previous to independence this territory gained a significant and strategic importance due to its geographic location to commercialize different products and as such became a center of disputes between European cities that wanted to take advantage of this location. Caribbean population by that time developed social practices and economic strategies such as smuggling and in their daily lives they had the opportunity to benefit from political and economic contexts surrounding them.

Key words: Caribbean, Mercantile Exchange, Social Practices and Smuggling

\section{Introducción}

La independencia fue un proceso que durante el siglo XIX produjo significativos impactos para los habitantes del Caribe. Sin embargo, es necesario precisar el hecho de que, la antesala de este acontecimiento tuvo sus raíces en las transformaciones que un siglo antes empezaron a gestarse tanto a nivel de las colonias americanas, como a nivel de los imperios europeos cuyas guerras por la apropiación de la explotación americana modificó el mapa de dominación que habían sostenido los españoles durante trescientos años.

Artículo de reflexión según clasificación Colciencias. 
Mapa 1. Rutas mercantilistas del Caribe durante el período colonial

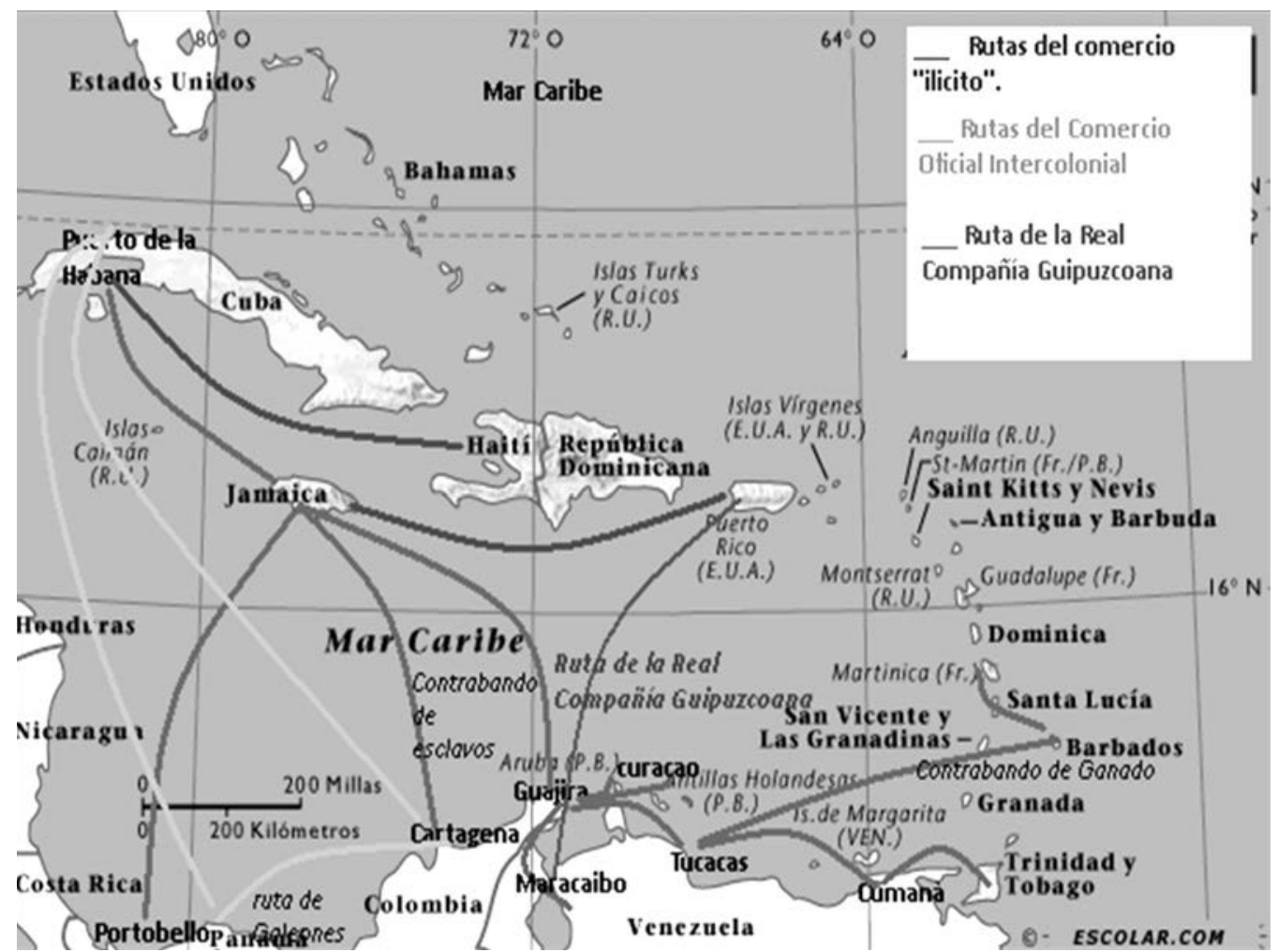

Fuentes: Araúz Monfante, Celestino Andrés: El contrabando holandés en el Caribe durante la primera mitad del siglo XVIII, Vol. II, Biblioteca de la Academia Nacional de la Historia Caracas, 1984. Pág. 343. /Aizpurua Ramón, "Las mulas venezolanas y el Caribe Oriental del siglo XVIII: Datos para una historia olvidada". Boletín Americanista. 38, Barcelona, 1988. Págs. 5- 15

El presente estudio busca escenificar el contexto caribeño a mediados del siglo XVIII ubicándolo como un período clave para entender las tensiones que se generaron años más tarde en el proceso independentista. Mediante el análisis de las prácticas y los intereses de los habitantes de la cuenca caribeña en contraste con las normas de la racionalidad económica y política española materializadas en las Reformas Borbónicas, se explicarán los fundamentos de algunas formas contestarias a las que se recurrieron con el fin de resistir las exigencias del decadente régimen colonialista. Así mismo, se mostrará la fuerte incidencia de la autonomía local y la construcción de redes sociales en las fronteras del Caribe sobre las tensiones que condujeron a los inicios de la independencia.

Este análisis se produce en el marco de los estudios sobre los espacios fronterizos del Caribe que se llevan a cabo al interior del grupo de investigación Frontera, Sociedad y Cultura en el Caribe y Latinoamérica de la Universidad de Cartagena. La preocupación fundamental en el presente artículo es dar cuenta del carácter histórico de los territorios y habitantes del Caribe durante el medio siglo antes de la independencia teniendo en cuenta el ejercicio de prácticas 
${ }^{1}$ Gonzales- Ripoll Navarro María, "Idea y representación del Caribe en la cartografia española en el siglo XVIII". Contrastes. No 12 Madrid. 2001- 2003. Pág. 83 Veáse a Brading David. "La España de los Borbones y su Imperio Americano". Leslie Bethell (ed). Historia de América Latina 2. América Latina Colonial: Europa y América en los siglos XVI, XVII, XVIII. Barcelona, Crítica/ Cambridge University Press, 1998. Pág. 85-126. Lynch John. El siglo XVIII. Historia de España XII Bar celona, Crítica. Págs. 408. sociales, políticas y económicas y el uso de formas contestarias (redes sociales, contrabando) para beneficiarse y/o resistir el sistema colonial y garantizar el bienestar particular o colectivo. El anterior discurso legitimó las primeras manifestaciones revolucionarias a fines del siglo XVIII, quienes se apoyaron en la necesidad de mantener "el bien común" como forma de resistir y desafiar el monopolio del sistema colonial.

El siglo XVIII fue para el Caribe un periodo de significativa importancia a nivel social, político y económico. En este siglo convergieron circunstancias y acontecimientos de carácter local e intercontinental que repercutieron en la cotidianidad y prácticas sociales de los habitantes de las diversas fronteras isleñas y continentales que pertenecían a su cuenca. El Caribe se había transformado en un espacio geográfico privilegiado para el contexto colonialista dominado por los europeos, ya que funcionaba como ruta obligada para el tránsito de mercancías a Nueva España y Perú. En ese sentido, observamos que el Caribe se convirtió en un punto esencial para la circulación mercantil, un escenario donde se enfrentaban los intentos españoles por monopolizar el comercio y la frecuente puesta en práctica de diversas formas de alianzas que facilitaron el contrabando con las potencias extranjeras que se habían ido apoderando de varias islas del Caribe.

Durante el medio siglo antes de la independencia el Caribe se fue transformando en un espacio de intercambio cultural donde los territorios dominados por las potencias europeas abrieron sus puertas a diversas formas de explotación tanto del territorio como de sus habitantes. Los circuitos mercantiles que paulatinamente se fueron consolidando permitieron la interacción de los habitantes de las colonias integradas en este espacio, de tal manera que la importancia que adquiría la región se debía no solo a su constitución como mundo económico base del comercio ultramarino, sino también a las relaciones y conexiones culturales que se establecían entre la tierra firme y el Caribe insular, entre los súbditos de la Corona española y los extranjeros franceses, ingleses y holandeses que habitaban a lo largo y ancho de la cuenca caribeña y de sus islas. ${ }^{1}$

En la segunda mitad del siglo XVIII la Corona española impulsó un proyecto reformador que buscaba transformaciones en las esferas comerciales, productivas, fiscales, militares y políticas. Es así como algunos años después Cuba y Puerto Rico empiezan a experimentar un florecimiento económico bajo el sistema de la plantación; por su parte, el resto de los espacios coloniales inicia 
una participación más abierta en la producción y el comercio de productos agrícolas y ganaderos a nivel internacional ${ }^{2}$.

A mediados del siglo XVIII se crean las llamadas Reformas Borbónicas españolas, que en principio buscaban restaurar el poder de la monarquía sobre los territorios de ultramar y terminó convirtiéndose en un detonante que abriría las puertas a los primeros focos de resistencia y conflictos alrededor de mantenerse dentro del régimen español u optar por la autonomía ${ }^{3}$. Una de las situaciones que crearon mayor tensión fue el monopolio del comercio ultramarino y el fortalecimiento del régimen fiscal a favor de la Corona, es decir, se modificó la situación de España como intermediario comercial de mercancías europeas y como responsable del comercio interno de sus colonias en América de manera que la Corona tomaría las riendas del mercantilismo que le estaba siendo disputado por metrópolis como Inglaterra, Francia y Holanda. España se convirtió en la creadora de un alineamiento comercial que favoreció fundamentalmente a la Corona cuya idea de "libre comercio" se redujo al intercambio de productos entre puertos intercontinentales del imperio dejando de lado la participación "legal" de otras potencias.

Es decir, las "novedosas" políticas comerciales que traían consigo las Reformas Borbónicas, no representaron otra cosa que la continuación del monopolio comercial de una metrópoli que no tenía la capacidad ni mercantil, ni naviera, para abastecer sus territorios. Al final, este hecho terminó favoreciendo los intereses de los poderes locales (elites, funcionarios públicos, militares, líderes nativos) e impulsando algunos mecanismos de resistencia como el contrabando, que permitían la sobrevivencia de diversos espacios del Caribe y la generación de prácticas socioculturales que lograban el sostenimiento activo de una autonomía frente a los lineamientos comerciales de la legislación hispana ${ }^{4}$.

En la mayoría de colonias hispanas ubicadas en el Caribe, los gobernadores, al igual que los vecinos y nativos, interponían sus intereses particulares a los intereses de la Corona. En estos términos es que se propone una lectura alterna al concepto tradicional del contrabando: una práctica que no implicaba una simple desobediencia a la norma, o al inminente caos y desorden de individuos incapaces por naturaleza de adaptarse a cualquier forma de organización económica, política o social, sino que obedece a la puesta en marcha de unos habitus colectivos ${ }^{5}$ construidos alrededor de los intereses particulares de autoridades locales y nativos que habitaban las fronteras del Caribe. Celestino

${ }^{2}$ Estrada Fabiola, "Marco y propósitos generales de las reformas Borbónicas" Grafia/Cuaderno de trabajo de los profesores del Departamento de Humanidades. Universidad Autónoma de Colombia. 2003. Pág. 6

${ }^{3}$ Estrada Fabiola, 2003: 3.

${ }^{4}$ Lance Grahn. Contraband, comerse and society in New Granada, 1713-1763. Disertación doctoral. Duke University. 1985. Pág. 408. Vease también "An Irresouble dilemma: smuggling in New Granada. 17171763". Isabel Sanclemente (Comp.). Memorias del 45 Congreso Internacional de Americanistas Uniandes. Págs. 21-54

5 Bordieu Pierre, El sentido práctico, Madrid. Taurus Humanidades.1991. Págs. 92-93. Este autor define los habitus colectivos como un sistemas de disposiciones duraderas y transferibles, estructuras estructuradas predispuestas para funcionar como estructuras esnar como estructuras esprincipios generadores y organizadores de prácticas y representaciones que pueden estar objetivamente adaptadas a su fin [....], objetivamente reguladas y regulares sin ser el producto de la obediencia regl...] pero acompañadas de un cálculo estratégico. 
Araúz, recrea la importancia de la práctica contrabandista en la economía de las fronteras del Caribe:

Sin duda alguna, fue el fenómeno del contrabando uno de los problemas más complejos que la corona española tuvo que afrontar en la administración de las Indias durante los siglos XVII y XVIII. Entre otras razones porque el desarrollo de América superó la capacidad de suministro por parte de la metrópoli, del mismo modo que España no tenía un mercado interior lo suficientemente amplio como para absorber los productos americanos. Además en las centurias antedichas, España estaba en desventaja naval con respecto a las potencias rivales, lo cual entorpeció las comunicaciones e hizo que aumentara el desabastecimiento en sus posesiones ultramarinas, máxime cuando la industria americana producía solo géneros bastos y carecía de artículos de primera necesidad $[\ldots]^{6}$.

Así mismo, Alfonso Múnera describe en los siguientes términos el contexto de las poblaciones caribeñas y su relación con la influencia y el escenario intercontinental europeo de ese momento:

Pues bien en ninguna parte la crisis se refleja tanto como en el mar Caribe [...]. Lo acontecido en estas islas define a fondo el carácter de las sociedades caribeñas colombianas. Nada se escapa a su influencia. Las cuantiosas inversiones en obras de seguridad y los cuantiosos gastos permanentes que demanda la plaza fuerte de Cartagena de Indias solo se explican en el siglo XVIII por la vecindad de las potencias europeas enemigas; así mismo la vastedad del tráfico ilegal que caracteriza la economía colonial de las provincias de Santa Marta y Cartagena tiene su origen en la inevitabilidad de las relaciones con Jamaica y Curazao." 7

${ }^{6}$ Araúz Celestino, El contrabando holandés en el Caribe, durante la primera mitad del siglo XVIII. Tomo I. Biblioteca de la Academia Nacional de la Historia. Caracas. 1984. Pág. 343. Pág. 21.

7 Munera Alfonso. "Ilegalidad y frontera". Adolfo Meisel (Comp.) Historia económica y social del Caribe Colombiano. Uninorte. Bogotá. 1994. Págs. $111-112$.
En ese sentido, se puede afirmar que si bien es cierto que el imperio español tenía un proyecto económico que beneficiaba solamente a la metrópoli, los habitantes del Caribe desarrollaron la capacidad de consolidar sus intereses particulares mediante la aprehensión de formas alternas como el contrabando, que les permitió tener una mejor posición en el escenario colonial dominado por los europeos. 
El presente artículo está estructurado en dos partes: en la primera se exponen las características fundamentales del escenario insular del Caribe sobre todo la influencia y ocupación de las potencias extranjeras sobre estos territorios. Se plantea la manera como los grupos que habitaron este territorio a mediados del siglo XVIII lograron crear formas contestarias para enfrentar las limitaciones del sistema colonial y garantizar el acceso a los beneficios generados por las economías del Caribe. En la segunda parte se abordan las particularidades de la circulación mercantil y las redes construidas por los actores sociales con el fin de beneficiarse del comercio del Caribe de tierra firme. En el artículo, en general, se rastrea la manera como cada provincia y poblado involucrado en la esfera de la circulación mercantil a través del contrabando, se inserta en la construcción de redes y alianzas de poder a nivel local. Así mismo, se analiza el contexto en el que tales construcciones favorecieron el desarrollo de prácticas y relaciones socioculturales que se volvieron fundamentales y redefinieron el carácter histórico con el que se vería este espacio en la posteridad. De manera que a la llegada del proceso independentista en el Caribe se fusionaron las corrientes de autonomía republicana con las prácticas alternas y de resistencia consolidadas durante el período colonial.

\section{LA RESISTENCIA Y EL USO DEL PODER EN EL CARIBE INSULAR}

El siglo XVIII abrió sus puertas con cambios sustanciales para las islas caribeñas. La guerra de sucesión trajo cambios trascendentales a las relaciones entre los habitantes de los diferentes territorios isleños y los colonos británicos, franceses y holandeses. Las Antillas se habían convertido en un apetecible espacio de disputa por el control sobre el comercio hispanoamericano ${ }^{8}$. El convenio que a comienzos de siglo celebraron españoles y franceses, complementado con las posteriores reformas y leyes económicas de los Borbones, no dejó vía libre para que los ingleses y holandeses participaran en el apetecible comercio de las indias españolas ${ }^{9}$. Es así como estas potencias marginadas, desde sus posesiones en las Antillas, inician la consolidación de sus relaciones comerciales con las islas españolas, es decir, los holandeses desde Curazao, los franceses desde Martinica y los británicos desde Jamaica. Esto les permitió establecer rutas comerciales que con frecuencia fueron base fundamental para el intercambio de productos prohibidos por la Corona (ver mapa 1.).

En consecuencia, los intereses comerciales llevaron a las potencias extranjeras a emprender una lucha por la obtención de un mayor número de territorios de las posesiones españolas con el fin de asentarse y consolidar sus intereses 
${ }^{10}$ Morales Carrion Arturo, Puerto Rico y la lucha por la hegemonía en el Caribe: Colonialismo y contrabando siglos XVI- XVIII. Puerto Rico. Universidad de Puerto Rico. 1995. Págs. 98- 103.

${ }^{11}$ Araúz, 1984: 71

12 Morales Arturo, 1995: 122-123.

${ }_{13}$ Belmonte Postigo, José Luis, "Notas sobre el tráfico de esclavos en Santiago de Cuba" Memorias (Revista digital de historia y arqueología desde el Caribe). Año 4. Barranquilla. Universidad del Norte. 2007. Pág. 5 en el Caribe. Por ejemplo, La Habana y Puerto Rico, estuvieron presentes en los planes de los ingleses, quienes veían en estas islas la posibilidad de levantar un emporio azucarero que compitiera con las posesiones españolas y francesas que monopolizaban, hasta ese momento, la producción de este género en el Caribe ${ }^{10}$.

Por su parte, el papel de las islas caribeñas no fue pasivo e inactivo frente al conflicto que se desarrollaba en el contexto internacional, pues al interior de ellas sus actores sociales también tenían sus propios intereses, y su participación en los intercambios mercantiles varió de acuerdo a la intencionalidad que los caracterizaba. Con frecuencia los habitantes del Caribe recurrieron a la formación de redes sociales para garantizar su acceso al contrabando tejiendo complejos entramados de relaciones y actividades donde se negociaban los diferentes intereses. Araúz explica que en el Caribe los extranjeros tenían, además de algunas autoridades locales, otros cómplices españoles, criollos, negros e indígenas, quienes les informaban oportunamente de cualquier peligro, o bien algunos, además de comprar o permutar sus productos, desempeñaban el papel de "metedores" o "bodoqueros", es decir, de introductores de las mercaderías tierra adentro. ${ }^{11}$

En las Antillas mayores, los extranjeros consolidaron circuitos comerciales donde compartían, en muchos casos, el trato clandestino con sus enemigos. La isla de Puerto Rico, por ejemplo, funcionó como centro de varias de las rutas comerciales del Caribe durante la colonia; allí, gobernadores y vecinos, súbditos de la corona española, construyeron acuerdos y formas alianzas que les permitían involucrarse en el contrabando con franceses, daneses y holandeses con el fin de monopolizar los beneficios y riquezas obtenidas del comercio de las ciudades y el aprovisionamiento de las embarcaciones que llegaban a sus puertos. Lo anterior nos permite observar como los habitantes de una isla como Puerto Rico desarrollaron prácticas socioeconómicas alternas al sistema colonial haciendo uso, precisamente, de herramientas funcionales para aquellos que ostentaban el acceso al poder y a la producción ${ }^{12}$. Así mismo, en la isla de Cuba, donde el gobernador había mantenido frecuentes tratos comerciales con Jamaica y Saint Domingue, se registran las luchas de daneses, franceses, británicos y suecos por introducir esclavos en el mercado habanero por la vía del contrabando ${ }^{13}$.

Es importante señalar el hecho de que más allá de la desobediencia o permisividad de las autoridades y vecinos que habitaban el Caribe insular, 
el contrabando y el contacto sociocultural con los extranjeros se convirtió en una práctica común que organizó redes y determinó la formación y mutación de alianzas entre los actores sociales que buscaban la provisión necesaria para sobrevivir al tiempo que generaban riquezas particulares ${ }^{14}$. El peligro que empezaron a atravesar estas prácticas con la llegada de la Reforma Borbónica del libre comercio a mediados del silgo XVIII articuló los intereses particulares con descontentos colectivos fundamentales en las revoluciones pre independentistas.

La isla francesa de Saint Domingue se convirtió en el proveedor principal de géneros que iban de contrabando a la posesión española de Santo Domingo, la cual había sido sacada de las rutas obligatorias recorridas por las flotas españolas que llegando al mar Caribe atracaban y descargaban sus géneros en Puerto Rico, Guadalupe, Cartagena y el Golfo del Darién, para luego ser llevados al Perú y Nueva España ${ }^{15}$.

La isla de Cuba también se mantuvo a la orden del día en la actividad contrabandista. La jerarquización propiciada por España entre sus diferentes puertos mediante la legislación, favoreció a La Habana, pues pasó a hacer parte de un selecto grupo de enclaves hispanos en el Caribe junto a puertos como Veracruz, Portobello, Cartagena y Panamá, siendo La Habana la más próspera por reunir en su bahía la escuadra de los galeones provenientes del Perú y la flota de la Nueva España. El puerto habanero se observa como un espacio acostumbrado a una cotidianidad agitada, gracias a la significativa actividad mercantil que se daba en la isla. Ahora bien, en este punto hay que mencionar que la existencia de algunos conflictos ocurridos durante los siglos XVII y XVIII, resienten fatalmente la relevancia adquirida por La Habana, sin embargo, como solución al abastecimiento que había dejado de recibir de España por la interrupción de la escuadra de galeones, la ocupación de holandeses e ingleses en las islas vecinas empieza a reemplazar la agitada actividad comercial de la isla de Cuba ${ }^{16}$. Esta transición permitió que la isla se viera frecuentada por holandeses e ingleses que venían de Jamaica; vecinos, alcaldes y gobernadores de La Habana aceptaban el soborno de los extranjeros a cambio que consintieran el tráfico ilícito en los puertos de la isla, entre ellos Puerto Príncipe, Bayamo, Manzanilla, Trinidad y Santa Cruz ${ }^{17}$.

Para el caso de la isla de Cuba es significativo resaltar el hecho de que muchas familias criollas poderosas que recibían en La Habana se vincularon al comercio a través de inversiones en compañías navieras que al mismo tiempo les
${ }^{14}$ Gutiérrez Meza Ruth, "Prácticas sociales y control territorial en el Caribe colombiano, 17501800. El caso del contrabando en la península de la Gujira". Historelo Revista regional y local. Vol. 3. N. 6. 2011. Págs. 39-65.

15 Ureña Rib Pedro, "Saint Domingue y Santo Domingo en el siglo XVIII: Aparición de dos identidades en una sola isla, en la lejana frontera de dos imperios" XI Congreso APFFUE, La Rioja, Logroño, 2002.

${ }^{16}$ Sorhegui D'Mares Arturo. "El puerto de La Habana: de principal enclave del comercio indiano, a cabecera de una economía de plantación". Ciudades porturias en la gran cuenca del Caribe. Jorge Enrique Elías Caro; Antonino Vidal Ortega (editores). Universidad del Magdalena/ Universidad del Norte. Barranquilla. 2010. Págs. 80-107.

${ }^{17}$ Arauz, 1984: 73-75 
permitían ser parte del contrabando. La historiadora Mercedes García afirma el hecho de que el enriquecimiento particular de los poderes locales en La Habana se debía en gran parte al desmesurado ejercicio del contrabando por parte de las compañías mercantilistas de su propiedad:

“(...) El gobernador de La Habana intenta con providencias universales remediar las introducciones de ropas y otros géneros y efectos, que en toda la Isla, el puerto de La Habana, y sus costas y surgideros se hacen frecuentemente y copiosamente, pero no logra conseguirlo por no tener en quien confiarse que no esté viciado en la misma relajación (...) Las embarcaciones de la Compañía que retornan de la Veracruz al puerto de carenas, traen cuanto quieren y las que vienen de Santo Domingo y Cartagena vienen llenas de ropa francesa, esto sucede con tanta frecuencia, que por las calles de La Habana, en carretillas, se vende ropa de todas calidades, orígenes y precios. En este comercio están empapados y lo encabezan distintos testaferros de Don Marrero [Presidente interino de la Compañía]; (....) Hay establecidos en la ciudad, almacenes públicos de todos estos géneros en las casas de Don Juan de Justis, director interino de la Compañía, en la de Don Joseph de la Guardia, en la de Don Manuel García de la Barrera, en la de Don Domingo Lizundía, en la de Don Joseph Cipriano de la Luz y en la de otros que abiertamente mantienen comercio con el Guárico, donde los provee la Casa Granchan, bajo la inteligencia y coligación de un comerciante francés llamado Dublan, que hace varios años se mantiene en este negocio". ${ }^{18}$

Del anterior fragmento se puede establecer la ubicación del contrabando como una forma contestaria de las élites habaneras frente a las prohibiciones y la racionalidad económica del régimen colonialista. Así mismo se explicitan las conexiones entre las colonias americanas para llevar a cabo un comercio alterno que no favorecía al decadente imperio español de la segunda mitad el siglo XVIII.

${ }^{18}$ García Mercedes. "La real compañía de comercio de por el Puerto de Carenas". Ciudades portuarias en la gran cuenca del Caribe. gran cuenca del Caribe. Historia, cultura, econo-
mía y sociedad. Elias Jorge; mía y sociedad. Elias Jorge Vidal Antonino (editores)

Universidad del MagdaleBarranquilla. 2010. Pág. 119.
Por otro lado, las islas de Curazao y St. Eustatius abrieron las puertas a los comerciantes privados de las diferentes colonias durante el siglo XVIII, aprovechando la situación de enfrentamientos y guerras, intermetrópolis que se daban en ese momento. Estas islas se convirtieron en desafíos para el monopolio mercantil que buscaba consolidar España en sus posesiones 
del Caribe. Desde estas islas se construyó un complejo organizacional de contrabandistas dirigido al establecimiento de una solida conexión mercantil con las posesiones hispanas de Tierra Firme. La formación de estos circuitos permitió a los diferentes actores sociales de las ciudades y poblados del Caribe, vincularse al contrabando de diversos géneros traídos de las posesiones extranjeras en pequeñas embarcaciones.

Desde la isla de Curazao los holandeses se conectaron con las costas de Venezuela, en especial el área de La Guaira y Caracas, así como con Maracaibo, Coro, Santa Marta y La Guajira. En esta última, la manera como el contrabando dinamizó la cotidianidad, se reflejó en el sentido que tuvo para sus habitantes la puesta en marcha de esta práctica que logró convertirse en un elemento fundamental de su desarrollo económico y sociocultural ${ }^{19}$.

El Caribe insular experimentó por un lado, el cambio de dominio y ocupación español por el de otras potencias europeas (Francia, Inglaterra, Holanda, etc.) y por el otro, los rigores de un régimen prohibitivo y en decadencia. Sin embargo, las estrategias y la autonomía de los habitantes de estos territorios les permitieron forjar formas sociales y económicas alternas para sobrevivir y enriquecerse, al punto de convertirlas en prácticas sociales interiorizadas y comunes para los grupos sociales que compartían la cuenca caribeña. En razón de esto, la práctica del contrabando debe recibir una lectura más allá de ser una desobediencia a la norma, para ubicarse dentro de las prácticas comunes que a diario y tradicionalmente realizaban los habitantes de las islas del Caribe.

\section{EL CARIBE DE TIERRA FIRME}

Con la presencia de los holandeses, ingleses y franceses ejerciendo la práctica contrabandista, el Caribe de tierra firme experimentó un alivio al sistema cerrado y monopolizador de la corona española. No sólo por los precios menos costosos, sino también por la variedad y la constancia con que llegaban los géneros a las costas de tierra firme, el contrabando se erige como una necesidad para los habitantes del Caribe.

Las costas de tierra firme, por ejemplo, mantuvieron un activo comercio con las islas francesas, inglesas y holandesas del mar Caribe. En la costa norte de Honduras, más específicamente en los puertos de Omoa, Caballos,

19 Para mayor profundidad del tema véase: AIZPURÚA AGUIRRE, Ramón: "El contrabando en la provincia de Venezuela en tiempos de la Compañía Guipuzcoana, 1730-1784", Revista-Review Interamericana, Vol. XIV, No $1-4$, pp. 4-19, Universidad Interamericana de Puerto Rico, 1984. ARAUZ MONFANTE, Celestino Andrés: "La acción ilegal de los holandeses en el Caribe y su impacto en las Antillas y Puerto Rico durante a primera mitad del siglo XVIII", Revista-Review Interamericana, Vol. XIV No 1-4, pp. 67-79, Universidad Interamericana de Puerto Rico, 1984. ARAUZ MONFANTE, Celestino Andrés: El contrabando holandés en el Caribe durante la primera mitad del siglo XVIII, dos Vols, Biblioteca de la Academin Nacional de la Historia, Caracas, 1984. Pág. 343. 
${ }^{20}$ Araúz, 1984: 85- 88.

${ }^{21}$ Araúz, 1984: 88

${ }^{22}$ Polo José; Gutiérrez Ruth. "Territorios, gentes y culturas libres en el Caribe continental Neogranadino

1700- 1850: una síntesis".

Historia Social del Caribe Colombiano, Polo José; Solano Sergio (editores)

La Carreta/Universidad de Cartagena. Medellín. 2011. Pp. 26-27.

${ }^{23}$ Langebaeck Carl, El diablo vestido de negro y los cunas del Darién. Jacobo Walburger y su breve noticia de la provincia de Darién de la ley y costum-

bres de sus indios, de la poca esperanza de plantar nuestra fe, y del número de sus naturales, 1748 . Uniandes. Bogotá. 2006 Págs. 16-23.
Trujillo, Sal y Cabo de las Tres Puntas, se acostumbra llevar a cabo tratos contrabandistas entre los extranjeros y los vecinos de Comayagua, Guatemala y Nicaragua. En el litoral comprendido entre el cabo Camarón, en Honduras, hasta la bahía Almirante, en Bocas del Toro, en el Istmo de Panamá, ingleses y holandeses en colaboración con zambos e indígenas mosquitos traficaban el palo de tinte, zarzaparrilla, añil, cacao, ganado vacuno, caballar y plata, entre otros géneros. ${ }^{20}$

El Istmo de Panamá, por su estratégica posición geográfica para el comercio ultramarino, se convirtió en la ruta acostumbrada para el tránsito de los metales preciosos que se despachaban desde el Virreinato del Perú hasta la península ibérica, por lo tanto, desde temprano despertó la ambición de corsarios y piratas holandeses, franceses e ingleses que no dudaron en acometer sus acciones contra este territorio, sobre todo por las tradicionales ferias que allí se celebraban. Sin embargo, en el siglo XVIII, estas ferias enfrentarán otros factores determinantes que conducirán a su ruina, ejemplo de ello fueron las guerras intermetrópolis y los efectos de la práctica contrabandista. El contrabando anglo-holandés en el istmo de Panamá se llevó a cabo con frecuencia en Portobello, donde se celebraban las ferias, el río Coclé, la isla de Naranjos, el río Mandinga y los puertos de Naos, San Buenaventura y Calidonia. $^{21}$

La provincia del Darién fue otro de los puntos de enérgico contrabando de lo que alguna vez fue la Real Audiencia de Panamá. Durante el siglo XVIII esta zona se había constituido en un fortín militar que buscaba sujetar a la población que habitaba el golfo de Uraba y controlar las relaciones mercantiles con las metrópolis extranjeras ${ }^{22}$. A los puertos del Darién arribaban escoceses, franceses e ingleses para intercambiar cacao, quina y plátano por espejos, cuchillos, pólvora y armas que usaban los nativos, en frecuentes ocasiones, contra las autoridades españolas ${ }^{23}$.

La preocupación de las autoridades coloniales quedó registrada en las decenas de informes que eran enviados a España, con el fin de que la Corona dispusiera normatividades que contralaran la práctica contrabandista. El misionero jesuita Jacobo Walburger quien estuvo en la zona a mediados del siglo XVIII informó en su breve noticia sobre la Provincia del Darién la intranquilidad que les generaba a los funcionarios locales las relaciones mercantiles "ilegales" de los nativos con los extranjeros: 
Yndios mezclados de unos pocos franceses, e Yngleses bastará para destruir todos tres fuertes, como en varias ocasiones ya se ha experimentado (...); no pocas veces sucede que algunos de mis indios se van con cinco, o siete pesos al Norte para ver si pueden topar embarcación Ynglesa (...) [afirmando de que los ingleses les] darán de valde la pólvora, munición, ropa, etca, y assi vale más tenerlo de valde, que comprarlo caro de los españoles, (...), el fin que llevaran sin duda será tomar a su tiempo posesión de esta provincia poco trabajo les costará el conseguir, como tienen todos los indios de su parte, y desesoso de que vengan $(\ldots . .)^{24}$.

Si bien es cierto el Darién había adquirido una significativa importancia para la Corona española esta no había logrado someter a la población nativa cuya autonomía les permitía resistir el pie de fuerza militar español y contrabandear sus productos con los extranjeros.

Las costas venezolanas también se convirtieron en una de las preocupaciones para la Corona no sólo por la frecuencia con que se hacia el comercio "ilícito", sino, además, por la amplia participación de las autoridades y gran parte de los sectores sociales que habitaban esa colonia. En los años comprendidos entre 1720 y 1722, la corona nombró jueces comisionados para investigar los tratos "ilegales" en los que, al parecer, se encontraban implicadas las autoridades locales venezolanas:

Cumpliendo con el encargo del Virrey, Beato y Olavarriaga levantaron extensas y detalladas sumarias sobre la actuación del gobernador Marcos Francisco de Betancourt, Diego de Matos y otras autoridades de Venezuela, sospechosas de consentir o efectuar, directa o indirectamente, el comercio ilícito ${ }^{25}$

El anterior fragmento es una muestra de cómo el contrabando se había extendido por las costas del Caribe, y en la mayoría de los casos había vinculado la esfera administrativa como medio para facilitar su puesta en práctica. Las represalias contra las autoridades que participaban en el contrabando implicaban con frecuencia, la destitución del cargo o la imposición de multas, sin embargo, estos castigos fueron mediados por los atenuados criterios y los vínculos de amistad que el funcionario podía tener con quienes les hacían las investigaciones. El caso analizado por Araúz nos permite recrear tal dinámica: 
${ }^{26}$ Araúz. 1984: 191- 192.

27 Aizpurúa, Ramón. “Las mulas venezolanas y el Caribe Oriental del siglo XVIII: Datos para una historia Olvidada". Boletín Americanista.38, Barcelona, 1988. Pág. 6.

${ }^{28}$ Ibíd. Págs. 12-13
Al parecer, Matos obtuvo el apoyo de Villalonga, por lo que no es de extrañar que los comisionados se inclinaran a favor del juez de comisios, quien prácticamente quedo libre de culpas, aunque algunos de sus soldados les impusieron fuertes multas al comprobar que defraudaron a la Real Hacienda en los comisios y se extralimitaron en la aplicación de la leyes. Las acusaciones recayeron sobre alcaldes, corregidores, tenientes, cabos a guerra $y$ otros funcionarios de los valles y costas, quienes, en una u otra forma, estaban implicados en el contrabando" 26

En la segunda mitad del siglo XVIII desde las costas de la actual Venezuela, se comerciaron mulas con Las Antillas orientales como Saint Domingue, que habitualmente se nutrieron de las mulas venezolanas para mover los molinos de los trapiches azucareros extranjeros. Las islas de Guadalupe y Martinica, se vieron precisadas a buscar mulas en tierra firme como también las posesiones inglesas de Granada, Tobago y Barbados. ${ }^{27}$

Las mulas venezolanas comerciadas con los extranjeros provenían de dos fuentes principales: los Llanos y la región coriana. En el primero de los casos, fueron claves los comerciantes tocuyanos y cororeños, que utilizaron la necesidad de sal que tenía la población del interior llanero y que era abundante en las costas corianas como móvil para ejercer el contrabando. Así, por ejemplo, un viaje que se suponía llevaba cargas de tabaco en recuas de mulas desde la región barinense y que de retorno vendrían cargadas de géneros, bastimentos y sal, resultaba en una operación de contrabando, ya que dichas mulas ocasionalmente nunca volvían, eran exportadas junto con el tabaco, gracias a los nexos comerciales que dichos comerciantes habían creado.

Los polos principales de dicho comercio eran la zona de Tucacas y las desembocaduras de los ríos Aroa, San Felipe y Tocuyo. En ocasiones, cuando el ganado comercializado era autóctono, entiéndase como de la propia región coriana, las mulas eran criadas en hatos cercanos a la costa, o en la península de Paraguaná. Por ejemplo, llama la atención que en zonas como Los Taques, el contrabando se realizaba directamente, sin esconder un supuesto comercio legal, como en parte sucedía en otras zonas. Esto indica que en la configuración de la práctica contrabandista, se crearon ejes comerciales que con los polos apuntados hacían de la costa coriana intermediario perfecto en el comercio exterior de mulas ${ }^{28}$. 
En las costas de la Nueva Granada (actual Colombia) el contrabando tampoco tardó en hacer presencia activa frente a las precarias importaciones provenientes de España, las que además no tenían punto de comparación respecto a los precios ofrecidos por los tratantes ingleses y holandeses de las islas del Caribe ${ }^{29}$. En el Caribe neogranadino, por ejemplo, la vida económica y la supervivencia de provincias como las de Cartagena, Santa Marta, y La Guajira estuvo mediada por el establecimiento de contactos e intereses de los diferentes sectores socio-raciales, que dieron como resultado la puesta en marcha de prácticas como el contrabando. Lo anterior debe entenderse partiendo del hecho de que dentro del campo comercial colonial, la realidad del Caribe no respondió a los referentes económicos de la legislación española, sino a los intereses de los sectores sociales que compartían la cuenca caribeña. Pese al intento del imperio borbónico por controlar esta práctica, el desencuentro entre la norma y la realidad estuvo a la orden del día, no solo por lo arraigada que estaban ciertas prácticas de resistencia en la sociedad, sino también porque los funcionarios reales que debían mantener el "orden" y hacer cumplir la normatividad terminaron envueltos, mediante su vinculación a redes de clientelismo, amistad y compadrazgo, al fenómeno del contrabando ${ }^{30}$.

Cartagena, por ejemplo, adquirió un valor estratégico para el imperio español por ser un lugar de recalada de los galeones procedentes de España que se dirigían a la feria de Portobello y Panamá, de tránsito hacia el Perú ${ }^{31}$. Sin embargo, mientras las flotas de galeones no abordaban las costas cartageneras, el contrabando de géneros como el azúcar, las harinas y el tabaco, era el que llenaba los mercados de este puerto español; algunos de los parajes frecuentados por el contrabando cerca a Cartagena fueron la isla de Barú, donde constantemente arribaban embarcaciones provenientes de Jamaica con negros, harinas y otras mercaderías que introducían por el caño de Cobao $^{32}$.

En Cartagena el contrabando tuvo un carácter contestatario que reflejaba el poder de las redes locales que se beneficiaban de esa práctica. La autonomía mercantil de la que habían gozado las elites cartageneras se enfrentaron a las limitantes exigencias del las Reformas Borbónicas de mediados del siglo XVIII, las cuales buscaban reducir el poder y el protagonismo de los poderes locales que encabezaban el comercio "ilegal" con las islas extranjeras del Caribe.

La península de La Guajira también llegó a convertirse en foco de activo contrabando y de gran preocupación para la Corona. Frecuentemente
${ }^{29}$ Laurent Muriel, "Nueva Francia y Nueva Granada frente al contrabando: reflexiones sobre el comercio ilícito durante el período colonial. Historia Critica N. 25, 2003. Universidad de los Andes. Bogotá Págs. 137- 156. Pág. 142 http:/redalyc.uaemex. $\mathrm{mx} / \mathrm{src}$ /inicio/ArtPdfRed. jsp?iCve $=81111333009$.

${ }^{30}$ Múnera. Pág. 135

${ }^{31}$ González Roberto, "Colombia y los vínculos históricos con el Caribe". Historia Caribe 9. Univerquilla 2004. Pág.42-43

32 Araúz. 1984: 93. 
${ }^{33}$ David Weber, La frontera española en América del Norte, México. Fondo de Cultura Económica. 2000.

Pág. 27. Según este autor "las fronteras son zonas de interacción entre dos o más culturas diferentes, como lugares en que estas culturas contienden entre

sí $y$ con su entorn físico para producir una dinámica única en el tiempo y en el espacio". José Polo Acuña analiza la escenificación de este concepto en las relaciones socioculturales entre nativos y criollos que ha-

bitaron en la península de

el siglo

XVIII y comienzos del XIX.

34 Polo Acuña José. Indi-

genas, Poderes y Media-

ciones en la Guajira en la

transición de la colonia

la republica (1750-1850).

Universidad Central de

Venezuela. Caracas. 2009. Tesis Doctoral.

35 Gutiérrez Meza Ruth. "Geografía, contrabando y fronteras. La Guajira a fines del siglo XVIII". Revista Amauta. Universidad del Atlántico. Barranquilla. 2010. Págs. 108.109.

36 Archivo General de la Nación. Milicias y marina. Fls. 453-468, 1770-1776 holandeses y franceses llegaban a los puertos guajiros de Bahía Honda, La Cruz, Portete, entre otros, a comerciar perlas, cacao, mulas, palo de tinte, cueros y algodón. Durante este periodo La Guajira se percibe como uno de los espacios fronterizos dentro del territorio neogranadino, caracterizado por su movilidad y porosidad social, política y económica ${ }^{33}$. Evidencia de ello es que a lo largo del siglo XVIII su cotidianidad está marcada por su estrecha vinculación con el contexto caribeño y la configuración de relaciones sociales con intereses particulares dentro de la península, los cuales originaron tradiciones y prácticas culturales en el marco de la búsqueda de beneficios económicos particulares.

El historiador José Polo Acuña plantea en su investigación sobre las relaciones inter étnicas en este territorio el hecho de que durante el siglo XVIII, la península de La Guajira se caracterizó por su diversidad geográfica y la existencia de unas comunidades nativas que se relacionaron de manera desigual con el hábitat que ocuparon ${ }^{34}$. En efecto, las fuentes historiográficas nos permiten pensar que durante este periodo en La Guajira se escenificaron constantes alianzas y conflictos relacionados con la lucha por el manejo de los recursos, la circulación mercantil y el control territorial ${ }^{35}$. Es así como el análisis del territorio vinculado a las actividades económicas y las prácticas sociales de la vida cotidiana encuentran un merecido espacio de análisis en el presente artículo.

Los puertos de la Alta Guajira fueron descritos por varios funcionarios, visitantes y "pacificadores" que llegaron a La Guajira durante la época colonial y registraron el frecuente contrabando en los puertos de La Cruz, Bahía Honda, Cabo de la Vela, entre otros. El capitán Antonio de Arévalo, por ejemplo, anotaba que en:

Toda la costa de Sotavento y Barlovento de la ciudad se dan fondo las balandras, tanto las extranjeras como las españolas, como es la Enea, Puerto de la Cruz Vieja, en el Pajar, Almidones, Manaure, Tucuraca, en la Uñama, en el Carrizal, Rincón del Carpintero, Cabo de la Vela, Yguanari, Bahía Hondita, Puerto Taroa, Punta Gallina, Paraujita y en toda las partes que le conviene, pero las más frecuentados para mantener el trato ilícito han sido en la Enea, en la rada del Río del Hacha [...] y camino real del Valle de Upar y tierra adentro $[\ldots]^{36}$ 
Lo interesante en el caso de la península de La Guajira fue la permanencia de expresiones de autonomía y resistencia vinculadas al contrabando y a otras formas de alianza en las que primaron los intereses de los poderes locales frente al régimen, en primera instancia colonial, y luego republicano ${ }^{37}$.

Santa Marta, por su parte vivió durante el período colonial las consecuencias de la limitante política mercantil de la Corona española ${ }^{38}$. Los funcionarios locales con frecuencia registraban en sus informes las dificultades que atravesaba la provincia para mantenerse provista de los géneros necesarios para la supervivencia de la población. Esto debido a que Santa Marta hasta la segunda mitad del siglo XVIII no fue un puerto autorizado por la Corona para realizar actividades mercantiles ${ }^{39}$.

Frente a esta situación Santa Marta termina optando por hacer del contrabando su mayor fuente de aprovisionamiento y acumulación de riqueza. Sujeta a una legislación prohibitiva que no tenía la capacidad para nutrir las diversas provincias que estaban bajo su orden Santa Marta practica un contrabando abierto respondiendo a las necesidades locales y no a la normatividad española. ${ }^{40}$ El contrabando en Santa Marta organiza alianzas y redes entre los actores sociales y es justificada como una práctica social necesaria frente a la racionalidad económica de un régimen prohibitivo y monopolista como el español. Durante el siglo XVIII, los gobernadores de Santa Marta respaldaron abiertamente el contrabando. Algunos como Diego Peredo, Alonso Valera y Cristóbal Vélez de Guevara, así como el obispo Luis Martínez de Gayoso, se dedicaron a un abierto contrabando con extranjeros franceses, ingleses y holandeses que llegaban a los puertos de esta provincia interesados en el carey y el palo de tinte. ${ }^{41}$

La construcción de redes sociales y la consolidación de los circuitos mercantiles vinculados al contrabando en la provincia de Santa Marta se convirtieron en una práctica contestataria esencial para la supervivencia y la vida cotidiana de los pobladores. Aun llegada la ola de movimientos independentistas la provincia de Santa Marta se inclinó por la protección de sus intereses tradicionales frente a los desafíos de un nuevo proyecto como el republicano.

El contrabando y la construcción de redes en el Caribe con el fin de resistir la limitante normatividad borbona que intentaron implantar los españoles en la segunda mitad del siglo XVIII, se convertirá en uno de los elementos esenciales para tensionar las relaciones entre la metrópoli española y las

${ }^{37}$ Polo, 2009: 198 ${ }^{38}$ Grahn. Págs. 21-54 ${ }^{39}$ Múnera, 1994: 136

${ }^{40}$ Laurent, 2003: 143. 41 Araúz, 1984: 249. Julían. Pág. 110 
colonias del Caribe. Estas últimas se convertirán en un escenario activo donde se escenificará la lucha entre las corrientes independentistas y las fuerzas de la monarquía, entre los intereses locales y los proyectos de gobierno en disputa.

\section{CONCLUSIONES}

Podemos concluir, por lo tanto, que las poblaciones del Caribe insular y de tierra firme estuvieron estrechamente vinculadas a nivel comercial y sociocultural durante el siglo XVIII. Este vínculo económico y social se escenificó en la práctica contrabandista que a diario se llevaba a cabo en los diversos puertos y que conectaba a los actores sociales que participaban de su puesta en marcha.

En toda la extensa cuenca caribeña el impacto de las Reformas Borbónicas y el objetivo de reforzar el control sobre el territorio, la población y los recursos afrontó grandes dificultades y terminó convirtiéndose en un detonante que tensionó fuerzas en favor de la independencia. En primer lugar porque la ausencia de una capacidad mercantil y naviera por parte del imperio español impedía el fortalecimiento del monopolio comercial con las colonias del Caribe, y en segundo lugar, es pertinente señalar que los diversos actores sociales que compartían este territorio se preocuparon en mayor medida en satisfacer sus necesidades e intereses antes que cumplir las imposiciones de un imperio cuya crisis económica y militar la habían ubicado como una potencia de segundo orden incapaz de desarrollar una racionalidad económica que beneficiará los territorios ultramarinos.

\section{BIBLIOGRAFÍA}

Documentos: Archivo General de la Nación. Milicias y marina. Fls. 453- 468. 1770-1776

Aizpurua, Ramon. "Las mulas venezolanas y el Caribe Oriental del siglo XVIII: Datos para una Historia Olvidada”. Boletín Americanista.38, Barcelona, 1988. Pág. 6.

Araúz Celestino, El contrabando holandés en el Caribe, durante la primera mitad del siglo XVIII. Tomo I. Caracas. Biblioteca de la Academia Nacional de la Historia. 1984. Pág. 343. Pág.21.

"La acción ilegal de los holandeses en el Caribe y su impacto en las Antillas y Puerto Rico durante la primera mitad del siglo XVIII", Revista-Review Interamericana, Vol. XIV, No 1-4, págs. 67-79, Universidad Interamericana de Puerto Rico, 1984. 
Belmonte Postigo, José Luis, "Notas sobre el tráfico de esclavos en Santiago de Cuba". Memorias (Revista digital de historia y arqueología desde el Caribe). Año 4. Barranquilla. Universidad del Norte. 2007. Pág.5

Bordieu Pierre. El sentido práctico, Madrid. Taurus Humanidades. 1991. Pp. 451.

Brading David. "La España de los Borbones y su Imperio Americano". Leslie Bethell (ed). Historia de América Latina 2. América Latina Colonial: Europa y América en los siglos XVI, XVII, XVIII. Barcelona, Crítica/ Cambridge University Press, 1998. Págs. 85-126.

Estrada Fabiola. "Marco y propósitos generales de las Reformas Borbónicas" Grafia/Cuaderno de trabajo de los profesores del Departamento de Humanidades. Universidad autónoma de Colombia.2003 Pág. 3.

García Mercedes. "La real compañía de comercio de La Habana. Su actividad por el Puerto de Carenas". Ciudades portuarias en la gran cuenca del Caribe. Historia, cultura, economía y sociedad. Elias Jorge; Vidal Antonino (editores). Universidad del Magdalena/Universidad del Norte. Barranquilla. 2010. Págs. 112- 136.

Gonzales- Ripoll Navarro Maria. "Idea y representación del Caribe en la cartografía española en el siglo XVIII”. Contrastes. No 12. Madrid. 2001- 2003. Pág. 83

González Roberto. "Colombia y los vínculos históricos con el Caribe". Historia Caribe. 9. Barranquilla. Universidad del Atlántico.2004. Pág.42-43

Grahn Lance. Contraband, comerse and society in New Granada, 1713-1763. Disertación doctoral. Duke University. 1985. Pág. 408. Vease también "An Irresoluble dilemma: smuggling in New Granada. 1717-1763". Isabel Sanclemente (Comp.). Memorias del 45 Congreso Internacional de Americanistas. Uniandes. Pp. 21-54

Gutiérrez Meza Ruth. "Geografía, contrabando y fronteras La Guajira a fines del siglo XVIII". Revista Amauta. Universidad del Atlántico. Barranquilla. 2010. PP. 108.109.

. Prácticas sociales y control territorial en el Caribe colombiano, 17501800. El caso del contrabando en la península de La Guajira". Historelo Revista regional y local. Vol. 3. N. 6. 2011. Pág. 39-65.

Langebaeck Carl. El diablo vestido de negro y los cunas del Darién. Jacobo Walburger y su breve noticia de la provincia del Darién, de la ley y costumbres de sus indios, de la poca esperanza de plantar nuestra fe, y del número de sus naturales, 1748. Uniandes. Bogotá. 2006. Págs. 99- 100.

Laurent Muriel. "Nueva Francia y Nueva Granada frente al contrabando: reflexiones sobre el comercio ilícito durante el período colonial. Historia Crítica N. 25, 2003. Universidad de los Andes. Bogotá 137- 156. Pág. Pp. 143.http://redalyc.uaemex.mx/src/inicio/ArtPdfRed. jsp?iCve $=81111333009$.

Morales Carrion Arturo. Puerto Rico y la lucha por la hegemonía en el Caribe: Colonialismo y contrabando siglos XVI- XVIII. Puerto Rico. Universidad de Puerto Rico. 1995. Pág. 98- 103.

Múnera Alfonso. "Ilegalidad y frontera". Adolfo Meisel (Comp.). Historia Económica y Social del Caribe Colombiano. Uninorte. Bogotá. 1994. Págs. 111- 112.

PalObra №. 12. Agosto de 2010 - Julio de 2011 
Polo Acuña José. Indígenas, poderes y mediaciones en la Guajira en la transición de la colonia a la republica (1750- 1850). Universidad Central de Venezuela. Caracas. 2009. Tesis Doctoral.

Polo Jose; Gutiérrez Ruth. "Territorios, gentes y culturas libres en el Caribe continental neogranadino 1700- 1850: una síntesis". Historia Social del Caribe Colombiano, Polo José; Solano Sergio (editores). La Carreta/Universidad de Cartagena. Medellín. 2011. Pág. 13- 44.

Sorhegui D’Mares Arturo. "El puerto de La Habana: de principal enclave del comercio indiano, a cabecera de una economía de plantación". Ciudades portuarias en la gran cuenca del Caribe. Jorge Enrique Elías Caro; Antonino Vidal Ortega (editores). Universidad del Magdalena/ Universidad del Norte. 2010. Págs. 80-107.

Ureña Rib Pedro. "Saint Domingue y Santo Domingo en el siglo XVIII: Aparición de dos identidades en una sola isla, en la lejana frontera de dos imperios” XI Congreso APFFUE, La Rioja, Logroño, 2002.

David Weber. La frontera española en América del Norte, México. Fondo de Cultura Económica. 2000. Pág. 27. 


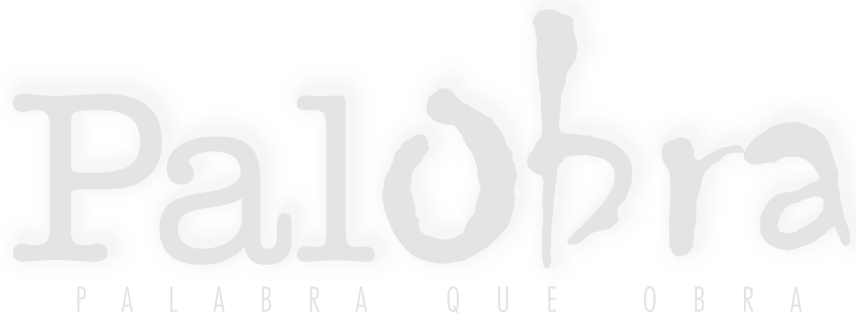

